\title{
A simple method to evaluate body condition score to maintain the optimal body weight in dogs
}

\author{
Ju Lan Chun, Han Tae Bang, Sang Yun Ji, Jin Young Jeong, Minji Kim, Byeonghyeon Kim, Sung Dae Lee, \\ Yoo Kyung Lee, Kondreddy Eswar Reddy and Ki Hyun Kim
}

National Institute of Animal Science, Rural Development Administration, Wanju 55365, Korea

\begin{abstract}
Overweight and obesity induce serious health problems that exert negative effects on dog's welfare. Body condition score (BCS) is a common method to evaluate the body fat mass in animals. By palpating and observing fats under the skin it is possible to predict animal's body fat accumulation condition. BCS is also a useful tool to estimate body fat composition in dogs. However, BCS can be subjective when it was performed by non-professionals like pet's owners. To develop a method to avoid the misevaluation of BCS twenty-four Beagles were enrolled and performed BCS evaluation. In addition, the length of chest and abdominal girths were measured. In correlation analysis, the sizes of chest and abdominal girth were significantly correlated with BCS. Especially, the difference and ratio of the chest and abdominal length were highly correlated with the BCS. With that, we suggested that this simple measurement of chest and abdominal girths by a measuring tape would be an effective method to estimate BCS scores in dogs that helps non-professionals to manage their own dog's nutritional condition by monitoring body fat accumulation condition.
\end{abstract}

Keywords: Body condition score, Dogs, Non-professional, Nutritional management, Weight control, Welfare

\section{Background}

Overweight and obesity have increased during the last decades $[1,2]$. In dogs, an excessive body fat accumulation has been also a serious concern and became a common health problem that affects on the quality of dog's life [3-6]. Unlike farm animals of which the nutritional balance is systemically managed by the feeding standard to achieve optimal productivity dogs living at home are dependent on owner's feeding regime $[7,8]$. Most of dog's owners aware the importance of adequate nutrition and activity but it is difficult for them to feed their dogs in an appropriate feeding level because of the variety of diets and sources of information available [9]. In addition, it is not easy for dog owners to accept the necessity of their own dog's weight reduction although they recognize well about the problematics of overweight and obesity [10-12].
For obtaining an absolute percentage of body nutritional condition the gold standard is cadaver analysis. However, it is not possible for live animals including pets [13]. Body condition scoring is the most common indirect method to evaluate the body fat accumulation of pets based on visual observation and palpation. Body condition score (BCS) systems which have different integral scales have similar evaluation standards for which detail descriptions and illustrations are provided for operators' information. Among BCS systems, 9-point scale BCS is commonly used in dogs $[1,14,15]$. For dogs, the corresponding BCS of obesity is the score 8 and 9 , and the ideal weight corresponds to 4 and 5 in the 9-point scale BCS system [15]. According to the American Veterinary Medical Association (AVMA) obesity is when a dog is over $30 \%$ above its ideal weight [16].

BCS has been confirmed to be a semi-quantitative tool to assess

Received: Nov 1,2019 Revised: Nov 6,2019 Accepted: Nov 8,2019

"Corresponding author: Ki Hyun Kim, National Institute of Animal Science, Rural Development Administration, Wanju 55365, Korea. Tel: +82-63-238-7473, E-mail: kihyun@korea.kr

This is an Open Access article distributed under the terms of the Creative Commons Attribution Non-Commercial License (http://creativecommons.org/licenses/by$\mathrm{nc} / 4.0 /$ ) which permits unrestricted non-commercial use, distribution, and reproduction in any medium, provided the original work is properly cited.

Copyright (C) 2019 Korean Society of Animal Science and Technology. 
body fat composition related with dog's health condition. Recent studies showed that BCS can estimate the body fat and it was supported by dual-energy X-ray absorptiometry (DEXA) and deuterium oxide $\left(\mathrm{D}_{2} \mathrm{O}\right)[15,17]$. BCS would be also an alternative tool to predict a certain disease. For example, an indirect association with survival time of lymphoma can be reflected by BCS when it is underweight at the time of diagnosis [18]. In addition, dogs have calcium oxalate uroliths when they had significantly greater median BCS [19]. The measurement of interleukin-6 and monocyte chemoattractant protein-1 concentrations in fasting plasma showed that inflammation would be associated with BCS and suggested that certain markers of inflammation increase with BCS [20]. There was also a positive correlation between insulin-like growth factor-1 (IGF-1) and the BCS in healthy dogs and a negative correlation between the ratio IFG-1/26SP and the BCS in chronic diseases [21].

Descriptions and illustrations provided in BCS systems help operators to assess dog's body condition even though they are not experienced veterinarians. However, there are often misevaluations by subjective impression of dog's owner although the evaluation of BCS has to be an objective assessment. It has been reported that the dog's owners evaluated their dog's BCS significantly lower than those by the veterinarians even with BCS description chart $[9,11,22]$. BCS would be the most convenient method to evaluate the nutritional body status of dogs. However, the subjective opinions of dog's owners can be an obstacle to obtain objective evaluations of BCS. The present study suggested that a simple measurement of body sizes can resolve the misevaluation issue of BCS by eliminating subjective impression, and be an alternative approach to evaluate BCS instead of palatable and observation.

\section{Materials and Methods}

\section{Ethics statement}

All animal experiments were approved by the Institutional Animal Care and Use Committee of the National Institute of Animal Science, Korea (Approval number: NIAS20191665). Animal experiments were followed strictly according to the approved protocols and dogs were monitored by veterinarian in need.

\section{Animals}

All dogs were maintained in separated cages with a temperature and ventilation control system. Two years old of twenty - four healthy Beagles were enrolled. Dogs were fed commercial diets twice a day, provided water ad libitum and exercised once a day in outdoor. In the normal weight group $\operatorname{dogs}(\mathrm{n}=7)$ were provided $830 \mathrm{kcal} /$ day which is the daily energy requirement and in the gaining weight group dogs $(\mathrm{n}=17)$ were provided $996 \mathrm{kcal} /$ day which is $20 \%$ more than daily energy requirement. The body weights were measured once a week.

\section{BCS}

The nine-scale body condition scoring system was used. BCS was evaluated once a week for 16 weeks that was performed according to the descriptions and illustrations provided by World Small Animal Veterinary Association (WSAVA). For each dog BCS was assessed by at least two persons who were learned the BCS evaluation technique from a veterinarian. The body condition of dogs was classified ; "too thin" which is in BCS 1-3 scales had easily visible and palpable bones with no or less fat, and their waist and abdominal tuck were obvious when viewed from top and side, "Ideal" which is in BCS 4 and 5 scales had bones with slight fat covering and an apparent waist and abdomen duck, and "Overweight" and "Obese" which are in BCS 6-9 scales had heavy fat covered ribs, absence of waist and obvious abdominal distension.

\section{Measurement of chest and abdominal girths}

The chest and abdominal girths were measured by using a measuring tape with no pulling. The chest girth was measured around the broadest region of the chest and over the back. The abdominal girth was measured around the waist directly in front of rear legs. The body sizes were measured once a week for 16 weeks when BCS was evaluated.

\section{Statistical analysis}

The significant difference between the body size and BCS were statistically analyzed using the PROC GLM of SAS (SAS Inst. Inc., Cary, NC, USA). The post hoc test were performed by Tukey range test to analyze the significant difference among BCS scores. The correlation between the sizes of chest and abdominal girths and the scales of BCS was analyzed by Pearson correlation analysis to investigate the relationship of body sizes and BCS scores.

\section{Results and Discussion}

The excessive body fat accumulation induces overweight and obesity that impairs the quality of life and lifespan in dogs. BCS is a numeric evaluation system and has been used to estimate the body fat accumulation condition. For monitoring the nutritional status of cows BCS has been used to estimate body fat condition. Body energy is stored at like back, tail head, pins, hooks ribs and brisket and it is highly related with the productivity of cows [23]. In dogs, there were also a similar method to examine body fat composition [24]. Since overweight has become one of serious health issues in dogs the need of nutritional cares for individual dogs has been even increased. Global nutrition guidelines of WSAVA provide descrip- 
JAST

tions, images and movies of the usage of BCS that allow people to learn how evaluate dog's body condition (www.WSAVA.org). However, there is a problem that the BCS can be misevaluated depending on the operator's proficiency [11]. Therefore, this study suggested a simple and objective method to estimate BCS in dogs. BCS were evaluated for 16 weeks. All of BCS scores which were evaluated in twenty - four dogs were listed in Table 1. BCS scales were classified into four different categories in which BCS 3 is "too thin", 4 and 5 are "ideal", 6 and 7 are "overweight" and 8 is "obese" based on the weight management program of WSAVA. In total, about $46 \%$ were the ideal condition (BCS 4 and 6) and $42.2 \%$ were in overweight or obese condition (BCS 7 or 8).

$\mathrm{BCS}$ is based on the description of the body morphology to

Table 1. BCS evaluations in twenty-four dogs for 16-weeks

\begin{tabular}{ccccccc}
\hline & Too thin & \multicolumn{2}{c}{ Ideal } & \multicolumn{2}{c}{ Overweight } & Obese \\
\hline BCS $(\mathrm{n})$ & 3 & 4 & 5 & 6 & 7 & 8 \\
Male & 27 & 41 & 54 & 66 & 21 & 7 \\
Female & 14 & 29 & 42 & 36 & 19 & 4 \\
Total & 41 & 70 & 96 & 102 & 40 & 11 \\
\hline
\end{tabular}

Values are the number of dogs in the scores of BCS for 16-weeks.

$\mathrm{BCS}$, body condition score. palpate and observe fats under the skin. This non-numeric evaluation of BCS induces subjective opinions from operators [10, 11]. The palpable body fats were evaluated around ribs, lumbar vertebrae and pelvic bones including the abdominal tuck existence. Meanwhile the operators evaluated dog's waist by bare eyes to check whether abdominal tuck is present or not. To find a solution of the misevaluation problem of BCS we measured the chest and abdominal girths to characterize the detail body sizes of dogs (Table 2). Sizes of chest and abdominal girths were significantly different based on the BCS scores. However, the body sizes of dogs were variable depending on the size of an individual dog. Therefore, a single measurement of chest or abdominal girth is highly relative that would not be an objective parameter to predict BCS in dogs.

In this study we observed that the abdominal tuck is getting decreased during dogs became overweight. The dogs with BCS 7 or 8 had almost a flat torso without the visible abdominal tuck. Next, the difference of chest and abdominal girth was calculated. The difference between chest and abdominal girths was significantly decreased when dogs were become overweight or obesity (Table 2). After that, we investigated the ratio of abdominal to chest girth and the ratio of chest to abdominal girth. The ratios between chest and abdominal girths were significantly related with BCS scores

Table 2. The body sizes and BCS evaluations in twenty-four dogs for 16-weeks

\begin{tabular}{|c|c|c|c|c|c|c|c|c|c|}
\hline & & \multicolumn{6}{|c|}{ BCS (means) } & \multirow{3}{*}{ SEM } & \multirow{3}{*}{$p$-value } \\
\hline & & \multirow{2}{*}{$\frac{\text { Too thin }}{3}$} & \multicolumn{2}{|c|}{ Ideal } & \multicolumn{2}{|c|}{ Overweight } & \multirow{2}{*}{$\begin{array}{c}\text { Obese } \\
8\end{array}$} & & \\
\hline & & & 4 & 5 & 6 & 7 & & & \\
\hline \multirow[t]{3}{*}{ Chest girth $(\mathrm{cm})$} & Female & 47.4 & 47.6 & 49.3 & 52.2 & 53.7 & 56.4 & 0.3 & $<.001$ \\
\hline & Male & 47.9 & 48.4 & 49.4 & 51.3 & 52.5 & 55.1 & 0.2 & \\
\hline & Pooled & $47.7^{\mathrm{e}}$ & $48.1^{\mathrm{e}}$ & $49.4^{d}$ & $51.6^{c}$ & $53.0^{\mathrm{b}}$ & $55.5^{\mathrm{a}}$ & 0.2 & \\
\hline \multirow[t]{3}{*}{ Abdominal girth $(\mathrm{cm})$} & Female & 32.4 & 34.6 & 36.5 & 40.0 & 44.3 & 49.5 & 0.4 & $<.001$ \\
\hline & Male & 34.7 & 35.6 & 37.9 & 40.4 & 43.9 & 48.0 & 0.3 & \\
\hline & Pooled & $33.9^{f}$ & $35.2^{\mathrm{e}}$ & $37.3^{\mathrm{d}}$ & $40.3^{c}$ & $44.1^{\mathrm{b}}$ & $48.5^{\mathrm{a}}$ & 0.2 & \\
\hline \multirow{3}{*}{$\begin{array}{l}\text { Difference between } \\
\text { chest and abdominal } \\
\text { girth }(\mathrm{cm})\end{array}$} & Female & 14.9 & 13.0 & 12.8 & 12.2 & 9.4 & 6.9 & 0.2 & $<.001$ \\
\hline & Male & 13.2 & 12.8 & 11.5 & 10.9 & 8.6 & 7.1 & 0.2 & \\
\hline & Pooled & $13.8^{\mathrm{a}}$ & $12.9^{b}$ & $12.1^{\mathrm{c}}$ & $11.4^{\mathrm{d}}$ & $9.0^{\mathrm{e}}$ & $7.0^{f}$ & 0.1 & \\
\hline \multirow{3}{*}{$\begin{array}{l}\text { Ratio of abdominal to } \\
\text { chest girth }\end{array}$} & Female & 0.7 & 0.7 & 0.7 & 0.8 & 0.8 & 0.9 & 0.0 & $<.001$ \\
\hline & Male & 0.7 & 0.7 & 0.8 & 0.8 & 0.8 & 0.9 & 0.0 & \\
\hline & Pooled & $0.7^{e}$ & $0.7^{e}$ & $0.8^{d}$ & $0.8^{c}$ & $0.8^{b}$ & $0.9^{\mathrm{a}}$ & 0.0 & \\
\hline \multirow{3}{*}{$\begin{array}{l}\text { Ratio of chest to } \\
\text { abdominal girth }\end{array}$} & Female & 1.5 & 1.4 & 1.4 & 1.3 & 1.2 & 1.1 & 0.0 & $<.001$ \\
\hline & Male & 1.4 & 1.4 & 1.3 & 1.3 & 1.2 & 1.1 & 0.0 & \\
\hline & Pooled & $1.4^{\mathrm{a}}$ & $1.4^{\mathrm{b}}$ & $1.3^{\mathrm{c}}$ & $1.3^{\mathrm{d}}$ & $1.2^{\mathrm{e}}$ & $1.1^{f}$ & 0.0 & \\
\hline
\end{tabular}

${ }^{a-f}$ Means with different superscripts within the columns are significantly different $(p<0.001)$

BCS, body condition score; SEM, standard error of mean. 
Table 3. The correlation coefficients between BCS and the body sizes

\begin{tabular}{lcccccc}
\hline & BCS & Chest girth & Abdominal girth & $\begin{array}{c}\text { Difference between chest } \\
\text { and abdominal girth }\end{array}$ & $\begin{array}{c}\text { Ratio of abdominal to } \\
\text { chest girth }\end{array}$ & $\begin{array}{c}\text { Ratio of chest to } \\
\text { abdominal girth }\end{array}$ \\
\hline $\begin{array}{l}\text { Pearson's } \\
\text { correlation coefficients }\end{array}$ & 1 & $.718^{*}$ & $.847^{*}$ & $-.569^{*}$ & $.686^{*}$ & $-.689^{*}$ \\
$p$-value & - & 0.001 & 0.001 & 0.001 & 0.001 & 0.001 \\
\hline
\end{tabular}

BCS, body condition score.

The correlation coefficient is significant at 0.05 .

from 3 to 8 (Table 2). To define the correlation between body sizes and BCS the Pearson's correlation efficient was analyzed (Table 3). We found that the difference and the ratio between chest and abdominal girths are significantly correlated with BCS scales. Together, it suggested that BCS scales can be predicted based on the difference and the ratio between chest and abdominal girths. In terms of simplicity of which subtraction and division the difference of chest and abdominal girths would be a convenient method to predict $\mathrm{BCS}$ in dogs.

Excessive energy intake induces the accumulation of extra body fats and would induce various health problems that affect serious impacts on dog's welfare [24]. For maintaining the optimal body fat composition, it is essential to monitor dog's body condition regularly that will prevent dogs from becoming overweight [25] Although BCS is an effective and a common method to evaluate body fat composition it can be misevaluated when it is performed by a non - professional like pet's owners because of the subjective impression. The present study showed that the body sizes of dogs can be obtained by a simple measuring tape and the difference of chest and abdominal girths is easily calculated. Moreover, the difference of chest and abdominal girth were able to predict BCS scales with a statistical significance. With that, a person who is not a veterinarian or a trained professional can evaluate dog's BCS. In other words, pet dog's owners who have no knowledge of BCS would be able to evaluate their own dog's BCS using this simple method. This finding would contribute to protect dog's welfare against overweight or obesity which could cause serious health problems and expensive veterinary medical cost to dog's owners.

\section{Competing interests}

No potential conflict of interest relevant to this article was reported.

\section{Funding sources}

This research was supported by a grant "Cooperative Research Program of Center for Companion Animal Research (Project No. PJ013984012019)" from the National Institute of Animal Science, Rural Development Administration, Korea.

\section{Acknowledgements}

Authors acknowledge the 2019 RDA Fellowship Program of the
National Institute of Animal Science, Rural Development Administration, Korea.

\section{Availability of data and material}

Upon reasonable request, the datasets of this study can be available from the corresponding author.

\section{Authors' contributions}

Conceptualization: Chun JL, Kim KH.

Data curation: Bang HT.

Formal analysis: Kim $\mathrm{Mj}$, Lee YK.

Methodology: Jeong JY, Kim BH.

Validation: Ji SY.

Writing - original draft: Chun JL, Kim KH.

Writing - review \& editing: Lee SD, Reddy KE.

\section{Ethics approval and consent to participate}

The animal study design was approved by IACUC review board (Approval Number: NIAS20191665). We have read and understood your journal's policies, and we believe that neither the manuscript nor the study violates any of these. This manuscript has not been published and is not under consideration by another journal.

\section{ORCID}

Ju Lan Chun

Han Tae Bang

Sang Yun Ji

Jin Young Jeong

Min ji Kim

Byeonghyeon Kim

Sung Dae Lee

Yoo Kyung Lee Kondreddy Eswar Reddy

https://orcid.org/0000-0002-4618-586X https://orcid.org/0000-0003-0441-3542 https://orcid.org/0000-0001-7235-3655 https://orcid.org/0000-0002-8670-7036 https://orcid.org/0000-0003-2106-1921 https://orcid.org/0000-0001-9298-3160 https://orcid.org/0000-0002-9167-4099 https://orcid.org/0000-0002-9896-4152

$$
\text { https://orcid.org/0000-0003-2024-7724 }
$$

Ki Hyun Kim https://orcid.org/0000-0002-9834-2126

\section{References}

1. Kronfeld DS, Donoghue S, Glickman LT. Body condition and 
energy intakes of dogs in a referral teaching hospital. J Nutr. 1991;121:S157-8.

2. German AJ, Blackwell E, Evans M, Westgrath C. Overweight dogs are more likely to display undesirable behaviours: results of a large online survey of dog owners in the UK. J Nutr Sci. 2017;6:e14.

3. Kopelman PG. Obesity as a medical problem. Nature 2000;404:635-43.

4. Buckland EL, Corr SA, Abeyesinghe SM, Watches CM. Prioritisation of companion dog welfare issues using expert consensus. Anim Welf. 2014;23:39-46.

5. German AJ, Holden SL, Wiseman-Orr ML, Reid J, Nolan AM, Biourge $V$, et al. Quality of life is reduced in obese dogs but improves after successful weight loss. Vet J. 2012;192:42834.

6. Kipperman BS, German AJ. The responsibility of veterinarians to address companion animal obesity. Animals. 2018;8:143.

7. Kienzle E, Bergler R, Mandernach A. A comparison of the feeding behavior and the human-animal relationship in owners of normal and obese dogs.J Nutr. 1998;128:2779-82.

8. Krasuska M, Webb TL. How effective are interventions designed to help owners to change their behaviour so as to manage the weight of their companion dogs? A systematic review and meta-analysis. Prev Vet Med. 2018;159:40-50.

9. Gerstner K, Liesegang A. Survey: nutrition, body condition and activities of dogs in Switzerland. J Anim Physiol Anim Nutr. 2017;101:15-20.

10. German AJ, Holden SL, Morris PJ, Biourge V. Long-term follow-up after weight management in obese dogs: the role of diet in preventing regain. Vet J. 2012;192:65-70.

11. Eastland-Jones RC, German AJ, Holden SL, Biourge V, Pickavance LC. Owner misperception of canine body condition persists despite use of a body condition score chart. J Nutr Sci. 2014;3:E45.

12. Yam PS, Naughton G, Butowski CF, Root AL. Inaccurate assessment of canine body condition score, bodyweight, and pet food labels: a potential cause of inaccurate feeding. Vet Sci. 2017;4:30.

13. Wells JCK, Fewtrell MS. Measuring body composition. Arch Dis Child. 2006;91:612-7.

14. Roche JR, Kay JK, Friggens NC, Loor JJ, Berry DP. Assessing and managing body condition score for the prevention of met- abolic disease in dairy cows. Vet Clin North Am Food Anim Pract. 2013;29:323-36.

15. Laflamme D. Development and validation of a body condition score system for dogs. Canine Pract. 1997;22:10-15.

16. Nolen RS. AVMA addresses pet obesity, opioid abuse. 2018. https://www.avma.org/News/JAVMANews/Pages/180815b.aspx?utm_source=email-optin\&utm_medium=javma-news-180815\&utm_campaign=bod\&utm_ter$\mathrm{m}=$ link\&utm_content=pet-obesity. Accessed 16 Oct 2019.

17. Mawby DI, Bartges JW, d'Avignon A, Laflamme DP, Moyers TD, Cottrell T. Comparison of various methods for estimating body fat in dogs. J Am Anim Hosp Assoc. 2004;40:109-14.

18. Romano FR, Heinze CR, Barber LG, Mason JB, Freeman LM. Association between body condition score and cancer prognosis in dogs with lymphoma and Osteosarcoma. J Vet Intern Med. 2016;30:1179-86.

19. Kennedy SM, Lulich JP, Ritt MG, Furrow E. Comparison of body condition score and urinalysis variables between dogs with and without calcium oxalate uroliths. J Am Vet Med Assoc. 2016;249:1274-80.

20. Frank L, Mann S, Levine CB, Cummings BP, Wakshlag JJ. Increasing body condition score is positively associated interleukin-6 and monocyte chemoattractant protein-1 in Labrador retrievers. Vet Immunol Immunopathol. 2015;167:104-9.

21. Gerke I, Kaup FJ, Neumann S. Evaluation of serum insulin-like growth factor-1 and 26S proteasome concentrations in healthy dogs and dogs with chronic diseases depending on body condition score. Res Vet Sci. 2018;118:484-90.

22. Courcier EA, Mellor DJ, Thomson RM, Yam PS. A cross sectional study of the prevalence and risk factors for owner misperception of canine body shape in first opinion practice in Glasgow. Prev Vet Med. 2011;102:66-74.

23. Wiltbank JN, Rowden WW, Ingalls JE, Geegoey KE, Koch RM. Effect of energy level on reproductive phenomena of mature Hereford cows. J Anim Sci. 1962;21:219-25.

24. German AJ. The growing problem of obesity in dogs and cats. J Nutr. 2006;136:1940S-6S.

25. Santarossa A, Parr JM, Verbrugghe A. The importance of assessing body composition of dogs and cats and methods available for use in clinical practice. J Am Vet Med Assoc. 2017;251:521-9. 